\title{
Cuidados paliativos e espiritualidade no Sistema Único de Saúde: Uma Revisão sistemática da literatura
}

\author{
Italo Constâncio de Oliveira ${ }^{1}$, Pedro Walisson Gomes Feitosa ${ }^{2}$, Elaíne Apolinário dos Santos3, Milena Maria \\ Felipe Girão ${ }^{4}$, Érika Galvão de Oliveira ${ }^{5},{\text { Fábio Angelo do } \text { Carmo }^{6} \text {, Isadélia Constâncio de Oliveira }}^{7}$
}

Resumo: Os cuidados paliativos em comunhão à espiritualidade são instrumento de bem estar dos pacientes em estado terminal. Nesse viés, esta revisão da literatura busca compilar as perspectivas do exercício do cuidado paliativo no Brasil. Realizou-se uma busca na plataforma BVS com as palavras-chave "cuidado paliativo", "espiritualidade" e "SUS", tendo os resultados filtrados pelo protocolo PRISMA. Obteve-se 10 artigos originais que debatem sobre a relação do cuidado paliativo no Brasil e a espiritualidade. Conclui-se que o exercício dos cuidados paliativos são importantes à qualidade de vida dos pacientes e que os profissionais devem se ater aos eixos desse cuidado.

Palavras-chave: Cuidados Paliativos, Espiritualidade, SUS.

\section{Palliative care and spirituality in the Unified Health System: A systematic review of the literature}

\begin{abstract}
Palliative care in communion with spirituality are instruments of patients' in terminal state well-being. This literature revision lists perspectives of palliative care exercise in Brazil. It was searched on BVS platform the keywords "palliative care", "spirituality" and "SUS", having results filtered through PRISMA protocol. It was obtained 10 original articles that debate about palliative care in Brazil and spirituality. The conclusion is that palliative care is important to patients' life quality and that professionals have to execute the palliative care methods.
\end{abstract}

Keywords: Palliative care, Spirituality, SUS.

\section{Introdução}

O sentido da vida é a busca que move o ser humano para manter o real motivo de viver e existir. É nessa perspectiva que, a espiritualidade proporciona uma forma de resiliência para enfrentar as dificuldades de ordem psíquica e física (LIMA et al., 2009).

\footnotetext{
${ }^{1}$ Acadêmico de Medicina da Universidade Federal do Cariri, UFCA, Brasil. italo.constancio@outlook.com;

${ }^{2}$ Acadêmico de Medicina da Universidade Federal do Cariri, UFCA, Brasil. gomesfeitosa.walisson@ outlook.com;

${ }^{3}$ Acadêmica de Medicina da Universidade Federal do Cariri, UFCA, Brasil. elaineapolinariodossantos@ gmail.com;

${ }^{4}$ Acadêmica de Medicina da Universidade Federal do Cariri, UFCA, Brasil. milenamfg@ hotmail.com;

${ }^{5}$ Acadêmica de Enfermagem do Centro Universitário Doutor Leão Sampaio, Brasil. erikagalvaodeoliveira@gmail.com;

${ }^{6}$ Acadêmico de Fisioterapia do Centro Universitário Doutor Leão Sampaio, Brasil. fabioangelo11@gmail.com;

${ }^{7}$ Graduada em Medicina pela Universidade Federal do Cariri, UFCA, Brasil. Preceptora adjunta da Faculdade Integrada de Patos, FIP, Brasil. Médica da Saúde da Família e Comunidade. isadeliaconstancioshalom@gmail.com.
} 
A espiritualidade está no sentido que cada indivíduo atribui a existencia para encontrar motivos para viver. "Quem tem um por que viver pode suportar quase qualquer como" (FRANKL, 1985).

Não obstante dessa realidade, os cuidados paliativos vão muito além do uso de fármacos que amenizam a dor, visto isso ao esmiuçar o próprio termo "paliativo" que deriva do latim pallium, que significa manto. E etimologicamente, cuidados paliativos significam prover um manto e aquecer "aqueles que passam frio", uma vez que os pacientes não podem mais ser ajudados pela medicina curativa (PESSINI \& BERTACHINI, 2005). Desse modo, é possível perceber a intrínseca relação que existe entre corpo e cura e entre corpo e espiritualidade no cuidado a vida, e ainda como estratégia de enfrentamento para familiares de pacientes em cuidados paliativos.

O cuidado paliativo definido de acordo com a Organização Mundial da Saúde (2002), buscas aprimorar a qualidade de vida de pacientes e famílias que enfrentam problemas associados com doenças ameaçadoras da vida, através da prevenção e alívio do sofrimento, por meio de identificação precoce, tratamento da dor e outros problemas de ordem biopsicossocial e espiritual.

A partir da definição supracitada é possível denotar a amplitude da atenção necessária ao paciente e aos seus familiares, visto que em meio a doença e o sofrimento o paciente é o centro e o foco da família sendo que este último é tido como pilar de sustentação por buscar oferecer força e apoio no processo de saúde doença. Assim é dessa maneira que a família mostra ao doente que ele não enfrentará as dificuldades sozinho, além de melhorar a qualidade da vida que lhe resta (FERREIRA et al., 2008), e ainda apoia-se na perspectiva espiritual de que em situações de adoecimento, os familiares buscam a espiritualidade como uma forma de enfrentamento e de suporte emocional, como também para respostas das indagações que surgem durante esse processo (BOUSO et al., 2011).

No Brasil essa nova visão do cuidado introduziu-se ao fim dos anos 80 , no Rio Grande do Sul, com a criação do Serviço de Cuidados Paliativos que foi anexado ao Serviço da Dor no Hospital de Clínicas de Porto Alegre (SILVA, 2011). Mas, apesar do tempo percorrido no Brasil as pessoas ainda associam o termo cuidados paliativos às pessoas que estão em estado terminal. Todavia mesmo com essas associações que restringem o amplo aspecto dos cuidados paliativos, essa prática ganhou apoio e respaldo pelo Sistema Único de Saúde (SUS) que pela resolução no 
41, publicada em 23 de novembro pelo Ministério da Saúde no Diário Oficial, oficializa o uso dos cuidados paliativos em todos os hospitais públicos do Brasil e torna a prática uma política de saúde.

Vale ressaltar que no Brasil as ações de cuidado paliativos e espiritualidade, vão muito além da tradicionalidade tendo como exemplo a inserção de música como recurso de cuidado em que a música se insere nesse contexto como uma atividade que pode proporcionar cuidado, conforto emocional e espiritual, estímulo à memória afetiva, relaxamento, entretenimento e criatividade (OTHERO; COSTA, 2007; FOXGLOVE, 1999)

Logo, presume-se a importância de revisar e ampliar os estudos sobre as literaturas que evidenciam as relações da espiritualidade e os cuidados paliativos com o paciente em quaisquer circunstâncias.

\section{Metodologia}

Artigos publicados entre 2008 e 2018 e indexados no banco de dados da Biblioteca Virtual de Saúde (BVS) foram selecionados para este trabalho de revisão. As palavras-chave utilizadas foram: "Cuidados Paliativos" "Espiritualidade" "SUS", sendo incluídos, também, os seguintes limites: artigos em português, inglês ,espanhol e disponíveis na íntegra, trabalhos de outros desenhos metodológicos, como relatos de casos, séries de casos, revisões e comentários de literatura, e estudos não originais, incluindo editoriais, revisões, comunicações e cartas ao editor. O período de busca dos artigos ocorreu entre 30 de janeiro de 2019 e 10 de fevereiro de 2019.

A seleção dos artigos foi realizada por dois avaliadores independentes e, no caso de discordâncias, um terceiro examinador foi convocado para o consenso final. Cada artigo foi lido na Íntegra e suas informações foram dispostas em uma planilha, incluindo ano de publicação, autores, base de dados e periódico. Em seguida, os trabalhos foram submetidos a três testes de relevância composto por perguntas objetivas, que analisavam a relação do artigo com os objetivos propostos pela pesquisa consoante o protocolo descrito por MUÑOZ et al., 2002.

O primeiro teste de relevância consistia nas seguintes perguntas: $\mathrm{O}$ estudo está de acordo com o tema investigado? O estudo foi publicado dentro do período estipulado no 
projeto? O estudo foi publicado no idioma estipulado no projeto? O estudo aborda a solução do problema que está sendo investigado? O estudo foi incluso?

O segundo teste visava verificar a objetividade da metodologia empregada no estudo, tendo as seguintes perguntas: O problema de pesquisa está claro? Os objetivos do estudo têm relação com a questão que está sendo estudada? A metodologia está descrita com clareza e abrange todos os objetivos? Os resultados são compatíveis com a metodologia empregada? Existe acurácia nos resultados empregados? O estudo foi incluso?

No teste de relevância final, foram extraídas informações detalhadas de cada artigo selecionado, distribuindo-as em uma planilha com as seguintes questões: (a) Tema principal; (b) Tipo de pesquisa; (c) Amostra de estudo; (d) Metodologia adotada; (e) Análise estatística; (f) Resultados; (g) Conclusão. Para estudar os dados, a etapa seguinte envolveu a divisão das informações obtidas a partir da leitura de cada um dos trabalhos consoante interfaces históricas, políticas, psicológicas e biológicas para posterior discussão.

\section{Resultados}

Foram identificados inicialmente 17 artigos na busca eletrônica, que foram incluídos na amostra final após os testes de relevância e análise criteriosa na íntegra (Figura 1). As referências obtidas descrevem experiências de cuidados paliativos na saúde pública do país, refletindo aspectos psicológicos e sociais do paciente e da família (Tabela 1). 
Figura 1. Diagrama PRISMA

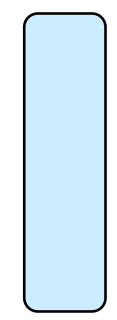

\section{Registros identificados por meio} de pesquisa no banco de dados

$$
\text { ( } n=17 \text { ) }
$$

Registros adicionais identificados por meio de outras fontes

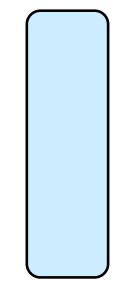

Registros após a remoção de duplicatas $(\mathrm{n}=17)$

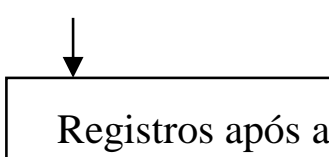

(.) $n$

Estudos incluídos em

uma síntese qualitativa

$$
(n=17)
$$


Tabela 1. Resultados por artigo selecionado.

\begin{tabular}{|c|c|c|c|c|c|}
\hline $\begin{array}{l}\text { Autor e } \\
\text { ano }\end{array}$ & Revista & Objetivo & Metodologia & Resultados & Conclusão \\
\hline $\begin{array}{l}\text { Silva et al. } \\
\text { (2008) }\end{array}$ & $\begin{array}{c}\text { Revista de } \\
\text { Enfermagem }\end{array}$ & $\begin{array}{c}\text { Apontar a } \\
\text { importância dos } \\
\text { valores } \\
\text { religiosos e } \\
\text { espirituais, bem } \\
\text { como a fé das } \\
\text { pessoas no } \\
\text { enfrentamento e } \\
\text { no } \\
\text { relacionamento } \\
\text { com os grandes } \\
\text { acontecimentos } \\
\text { da vida humana: } \\
\text { nascimento, dor, } \\
\text { sofrimento } \\
\text { humano e além- } \\
\text { vida. }\end{array}$ & $\begin{array}{l}\text { Utilizou-se a } \\
\text { abordagem } \\
\text { qualitativa } \\
\text { fundamentada } \\
\text { na } \\
\text { fenomenologia } \\
\text { existencial. } \\
\text { Foram } \\
\text { realizadas } \\
\text { entrevistas com } \\
\text { 10 familiares de } \\
\text { clientes em } \\
\text { seus domicílios, } \\
\text { no período de } \\
\text { janeiro de } 2006 \\
\text { a janeiro de } \\
\text { 2007, em uma } \\
\text { cidade situada } \\
\text { no noroeste do } \\
\text { Estado do } \\
\text { Paraná. } \\
\text { Apresenta-se } \\
\text { alguns de } \\
\text { valores } \\
\text { fundamentais } \\
\text { das religiões; } \\
\text { pontos } \\
\text { convergentes e } \\
\text { as suas } \\
\text { distinções sem } \\
\text { separar religião, } \\
\text { espiritualidade } \\
\text { e mística. } \\
\text { Também } \\
\text { delimita-se o } \\
\text { enfoque no } \\
\text { âmbito da } \\
\text { medicina esfera dos } \\
\text { cuidados de } \\
\text { assistência à } \\
\text { saúde e dos } \\
\text { cuidados } \\
\text { paliativos. } \\
\text { alguns } \\
\text { documentos } \\
\text { internacionais } \\
\text { que valorizam a } \\
\text { espiritualidade } \\
\text { ando }\end{array}$ & $\begin{array}{l}\text { Da linguagem } \\
\text { dos familiares, } \\
\text { emergiram três } \\
\text { categorias: } \\
\text { sentimentos } \\
\text { avivados nos } \\
\text { familiares ante a } \\
\text { descoberta do } \\
\text { diagnóstico; } \\
\text { compartilhar } \\
\text { com o ente } \\
\text { querido o } \\
\text { tratamento; e a } \\
\text { importância da } \\
\text { espiritualidade } \\
\text { para o } \\
\text { entendimento da } \\
\text { situação. }\end{array}$ & $\begin{array}{c}\text { Fundamentalment } \\
\text { e a } \\
\text { espiritualidade } \\
\text { tem a ver com a } \\
\text { busca } \\
\text { transcendente de } \\
\text { um sentido maior } \\
\text { no aparente } \\
\text { absurdo de } \\
\text { passarmos por } \\
\text { experiências de } \\
\text { dor, sofrimento, } \\
\text { perda, angústia e } \\
\text { até mesmo do } \\
\text { medo da morte. }\end{array}$ \\
\hline
\end{tabular}




\begin{tabular}{|c|c|c|c|c|c|}
\hline $\begin{array}{l}\text { Silva et al. } \\
\text { (2014) }\end{array}$ & $\begin{array}{c}\text { Revista } \\
\text { Eletrônica } \\
\text { de } \\
\text { Enfermagem }\end{array}$ & $\begin{array}{l}\text { Desvelar os } \\
\text { significados e } \\
\text { sentidos da } \\
\text { identidade } \\
\text { musical de } \\
\text { pacientes e } \\
\text { familiares sob } \\
\text { cuidados } \\
\text { paliativos } \\
\text { oncológicos. }\end{array}$ & $\begin{array}{c}\text { Foram } \\
\text { entrevistados, } \\
\text { individualment } \\
\text { e, } 12 \text { usuários } \\
\text { hospedados na } \\
\text { casa de apoio } \\
\text { da Rede } \\
\text { Feminina de } \\
\text { Combate ao } \\
\text { Câncer de } \\
\text { Maringá, que } \\
\text { integraram oito } \\
\text { encontros } \\
\text { musicais } \\
\text { realizados nos } \\
\text { meses de } \\
\text { janeiro e } \\
\text { fevereiro de } \\
2011 .\end{array}$ & $\begin{array}{c}\text { A identidade } \\
\text { musical dos } \\
\text { seres } \\
\text { evidenciados } \\
\text { reporta-se aos } \\
\text { estilos musicais } \\
\text { religioso e } \\
\text { sertanejo, que os } \\
\text { seus } \\
\text { significados e } \\
\text { sentidos estão } \\
\text { atrelados à sua } \\
\text { espiritualidade e } \\
\text { aos eventos } \\
\text { significativos de } \\
\text { sua } \\
\text { historicidade, e } \\
\text { que o seu estado } \\
\text { de } \\
\text { espírito/humor e } \\
\text { a reflexão } \\
\text { intermediada } \\
\text { pelas músicas } \\
\text { podem } \\
\text { influenciar a sua } \\
\text { escolha musical. }\end{array}$ & $\begin{array}{l}\text { Há necessidade } \\
\text { de se considerar a } \\
\text { identidade } \\
\text { musical e a } \\
\text { autonomização } \\
\text { na escolha } \\
\text { musical, que traz } \\
\text { consigo aspectos } \\
\text { existenciais, } \\
\text { sociais, culturais, } \\
\text { espirituais e } \\
\text { familiares, como } \\
\text { elementos } \\
\text { qualificadores do } \\
\text { cuidado de } \\
\text { Enfermagem em } \\
\text { cuidados } \\
\text { paliativos. }\end{array}$ \\
\hline $\begin{array}{l}\text { Cervelin, } \\
\text { Kruse } \\
(2014)\end{array}$ & $\begin{array}{l}\text { Escola Anna } \\
\text { Very de } \\
\text { Enfermagem }\end{array}$ & $\begin{array}{l}\text { Conhecer os } \\
\text { discursos sobre } \\
\text { espiritualidade e } \\
\text { religiosidade } \\
\text { que circulam } \\
\text { nos livros sobre } \\
\text { Cuidados } \\
\text { Paliativos, e } \\
\text { saber como tais } \\
\text { dispositivos } \\
\text { operam } \\
\text { produzindo } \\
\text { verdades. }\end{array}$ & $\begin{array}{c}\text { Análise textual } \\
\text { que realiza uma } \\
\text { aproximação } \\
\text { com o campo } \\
\text { dos Estudos } \\
\text { Culturais. O } \\
\text { corpus de } \\
\text { análise é } \\
\text { composto por } \\
\text { seis livros e um } \\
\text { manual. A } \\
\text { coleta dos } \\
\text { dados foi feita a } \\
\text { partir da leitura } \\
\text { interessada dos } \\
\text { livros. Para } \\
\text { realizar as } \\
\text { análises, } \\
\text { utilizou-se no } \\
\text { referencial de } \\
\text { Foucault. }\end{array}$ & $\begin{array}{c}\text { A pesquisa } \\
\text { destaca os livros } \\
\text { sobre Cuidados } \\
\text { Paliativos como } \\
\text { importantes } \\
\text { artefatos da } \\
\text { mídia, que } \\
\text { proporcionam a } \\
\text { circulação de } \\
\text { discursos tidos } \\
\text { como } \\
\text { verdadeiros. }\end{array}$ & $\begin{array}{c}\text { Os livros } \\
\text { apontam } \\
\text { vantagens de ser } \\
\text { religioso e/ou } \\
\text { espiritualizado. } \\
\text { Observa-se o } \\
\text { governo dos } \\
\text { sujeitos por meio } \\
\text { da religião e da } \\
\text { espiritualidade, } \\
\text { de forma a } \\
\text { conduzir suas } \\
\text { condutas e } \\
\text { influenciar o seu } \\
\text { modo de ser e } \\
\text { agir. . }\end{array}$ \\
\hline $\begin{array}{l}\text { Silva, } \\
\text { Marcon, } \\
\text { Sales } \\
(2014)\end{array}$ & $\begin{array}{c}\text { Revista } \\
\text { Brasileira de } \\
\text { Enfermagem }\end{array}$ & $\begin{array}{c}\text { Indicar a } \\
\text { percepção de } \\
\text { familiares } \\
\text { acompanhantes } \\
\text { de pacientes que } \\
\text { convivem com } \\
\text { o câncer e o } \\
\text { tratamento } \\
\text { antineoplásico } \\
\text { em uma casa de }\end{array}$ & $\begin{array}{c}\text { Os sujeitos } \\
\text { foram cinco } \\
\text { usuários da } \\
\text { casa de apoio } \\
\text { da Rede } \\
\text { Feminina de } \\
\text { Combate ao } \\
\text { Câncer de } \\
\text { Maringá, onde } \\
\text { foram }\end{array}$ & $\begin{array}{l}\text { Constatou-se } \\
\text { que o encontro } \\
\text { mediado pela } \\
\text { música pode } \\
\text { proporcionar } \\
\text { aos familiares } \\
\text { acompanhantes } \\
\text { um momento de } \\
\text { introspecção } \\
\text { existencial, que }\end{array}$ & $\begin{array}{l}\text { No contexto dos } \\
\text { cuidados } \\
\text { paliativos } \\
\text { oncológicos, } \\
\text { esses encontros } \\
\text { podem ampliar as } \\
\text { possibilidades de } \\
\text { integralização e } \\
\text { humanização do } \\
\text { cuidado de }\end{array}$ \\
\hline
\end{tabular}

411 Id on Line Rev. Mult. Psic. V.13, N. 45, p. 405-419, 2019 - ISSN 1981-1179 Edição eletrônica em http://idonline.emnuvens.com.br/id 


\begin{tabular}{|c|c|c|c|c|c|}
\hline & & $\begin{array}{c}\text { apoio, onde são } \\
\text { utilizados } \\
\text { encontros } \\
\text { musicais como } \\
\text { método de } \\
\text { tratamento }\end{array}$ & $\begin{array}{c}\text { realizados oito } \\
\text { encontros } \\
\text { musicais, } \\
\text { durante os } \\
\text { meses de } \\
\text { janeiro e } \\
\text { fevereiro de } \\
2011 .\end{array}$ & $\begin{array}{c}\text { os conduzem a } \\
\text { uma experiência } \\
\text { transcendental } \\
\text { no } \\
\text { enfrentamento } \\
\text { de sua condição } \\
\text { existencial, } \\
\text { incitando a } \\
\text { expressão de } \\
\text { subjetividades e } \\
\text { o desvelamento } \\
\text { de suas } \\
\text { necessidades } \\
\text { existenciais / } \\
\text { espirituais. }\end{array}$ & $\begin{array}{c}\text { enfermagem à } \\
\text { família, } \\
\text { subsidiando } \\
\text { conforto, reflexão } \\
\text { e motivação } \\
\text { diante das } \\
\text { adversidades } \\
\text { emergentes em } \\
\text { sua } \\
\text { temporalidade na } \\
\text { casa de apoio. }\end{array}$ \\
\hline $\begin{array}{c}\text { Seredynsk } \\
\text { yj et al. } \\
(2015)\end{array}$ & $\begin{array}{c}\text { Revista } \\
\text { Eletrônica } \\
\text { de } \\
\text { Enfermagem }\end{array}$ & $\begin{array}{l}\text { Compreender a } \\
\text { percepção que } \\
\text { os idosos, em } \\
\text { cuidados } \\
\text { paliativos } \\
\text { oncológicos, } \\
\text { possuíam do seu } \\
\text { autocuidado em } \\
\text { relação às } \\
\text { diferentes } \\
\text { etapas de } \\
\text { desenvolviment } \\
\text { o da doença e } \\
\text { como essa } \\
\text { interferia na } \\
\text { vida dos } \\
\text { mesmos. }\end{array}$ & $\begin{array}{c}\text { Trata-se de } \\
\text { pesquisa } \\
\text { qualitativa } \\
\text { utilizando a } \\
\text { história oral } \\
\text { temática com } \\
15 \text { idosos em } \\
\text { tratamento } \\
\text { quimioterápico } \\
\text { paliativo, em } \\
\text { uma instituição } \\
\text { de saúde. }\end{array}$ & $\begin{array}{l}\text { As categorias } \\
\text { que emergiram } \\
\text { foram: rede de } \\
\text { apoio social, } \\
\text { perspectiva para } \\
\text { o enfrentamento } \\
\text { da vida, } \\
\text { mudanças e } \\
\text { espiritualidade. }\end{array}$ & $\begin{array}{c}\text { Ressalta-se a } \\
\text { necessidade de } \\
\text { compreensão } \\
\text { desse processo } \\
\text { pelo pessoal de } \\
\text { enfermagem para } \\
\text { que as medidas a } \\
\text { serem } \\
\text { implementadas } \\
\text { passem a } \\
\text { contemplar todas } \\
\text { as implicações da } \\
\text { doença e visem a } \\
\text { melhora da } \\
\text { qualidade de } \\
\text { vida. }\end{array}$ \\
\hline $\begin{array}{l}\text { Júnior et } \\
\text { al. (2015) }\end{array}$ & $\begin{array}{l}\text { Revista } \\
\text { Bioética }\end{array}$ & $\begin{array}{c}\text { Conhecer a } \\
\text { importância que } \\
\text { médicos e } \\
\text { pacientes ali } \\
\text { atendidos } \\
\text { atribuem à } \\
\text { religião e à } \\
\text { espiritualidade, } \\
\text { bem como } \\
\text { identificar sua } \\
\text { relação com o } \\
\text { tratamento da } \\
\text { doença renal } \\
\text { crônica naquele } \\
\text { contexto } \\
\text { específico. }\end{array}$ & $\begin{array}{l}\text { Optou-se pela } \\
\text { pesquisa } \\
\text { qualitativa do } \\
\text { tipo } \\
\text { exploratório, e } \\
\text { pela entrevista } \\
\text { individual. }\end{array}$ & $\begin{array}{c}\text { Em relação ao } \\
\text { perfil religioso } \\
\text { dos } 10 \\
\text { entrevistados } \\
\text { portadores de } \\
\text { doença renal } \\
\text { crônica em } \\
\text { tratamento } \\
\text { dialítico no } \\
\text { Hospital das } \\
\text { Clínicas Samuel } \\
\text { Libânio, } 80 \% \text { se } \\
\text { declararam } \\
\text { católicos e } 20 \%, \\
\text { evangélicos. } \\
\text { Quanto ao } \\
\text { tempo de } \\
\text { diagnóstico da } \\
\text { doença foi de } \\
\text { 6,7 anos. Já em } \\
\text { relação ao } \\
\text { tempo de } \\
\text { tratamento, } \\
\text { calculou-se uma }\end{array}$ & $\begin{array}{l}\text { A religião é um } \\
\text { elemento } \\
\text { significativo e } \\
\text { relevante na } \\
\text { evolução da } \\
\text { doença renal } \\
\text { crônica, haja } \\
\text { vista sua } \\
\text { capacidade de } \\
\text { trazer conforto, } \\
\text { apoio, força e } \\
\text { esperança de } \\
\text { melhoria na vida } \\
\text { dos portadores. }\end{array}$ \\
\hline
\end{tabular}




\begin{tabular}{|c|c|c|c|c|c|}
\hline & & & & $\begin{array}{c}\text { média de } 3,9 \\
\text { anos }\end{array}$ & \\
\hline $\begin{array}{l}\text { Pérez- } \\
\text { Garcia } \\
(2016)\end{array}$ & $\begin{array}{c}\text { Enfermería: } \\
\text { Cuidados } \\
\text { Humanizado } \\
\text { s }\end{array}$ & $\begin{array}{l}\text { Compreender as } \\
\text { necessidades } \\
\text { espirituais dos } \\
\text { pacientes com } \\
\text { doença em fase } \\
\text { terminal e sua } \\
\text { relação com os } \\
\text { profissionais de } \\
\text { enfermagem. }\end{array}$ & $\begin{array}{l}\text { Utilizou como } \\
\text { recurso } \\
\text { metodológico } \\
\text { listagem de } \\
\text { conceitos } \\
\text { referentes às } \\
\text { necessidades } \\
\text { espirituais. }\end{array}$ & $\begin{array}{l}\text { Apareceram as } \\
\text { seguintes } \\
\text { respostas: Os } \\
\text { profissionais } \\
\text { não são } \\
\text { conscientes da } \\
\text { sua própria } \\
\text { espiritualidade; } \\
\text { Pela falta de } \\
\text { conhecimentos e } \\
\text { habilidades } \\
\text { nesses aspectos. }\end{array}$ & $\begin{array}{l}\text { A necessidade do } \\
\text { profissional estar } \\
\text { ciente da própria } \\
\text { espiritualidade, } \\
\text { para dessa forma } \\
\text { ser sensível a } \\
\text { espiritualidade do } \\
\text { paciente. }\end{array}$ \\
\hline $\begin{array}{l}\text { Arrieira et } \\
\text { al. }(2017)\end{array}$ & $\begin{array}{c}\text { Revista } \\
\text { Gaúcha de } \\
\text { Enfermagem }\end{array}$ & $\begin{array}{l}\text { Compreender o } \\
\text { sentido do } \\
\text { cuidado } \\
\text { espiritual para a } \\
\text { integralidade da } \\
\text { atenção à } \\
\text { pessoa e para a } \\
\text { equipe } \\
\text { interdisciplinar } \\
\text { de cuidados } \\
\text { paliativos. }\end{array}$ & $\begin{array}{c}\text { Baseada por } \\
\text { meio da } \\
\text { observação e } \\
\text { entrevistas } \\
\text { fenomenológica } \\
\text { s através das } \\
\text { informações } \\
\text { coletadas no } \\
\text { domicílio do } \\
\text { participante. }\end{array}$ & $\begin{array}{l}\text { Surgiram as } \\
\text { seguintes } \\
\text { categorias: } \\
\text { Sentido da } \\
\text { integralidade do } \\
\text { cuidado e } \mathrm{O} \\
\text { sentido da } \\
\text { espiritualidade } \\
\text { para os } \\
\text { profissionais } \\
\text { que cuidam de } \\
\text { pessoas em } \\
\text { tratamento } \\
\text { paliativo, com } \\
\text { suas } \\
\text { subcategorias. }\end{array}$ & $\begin{array}{c}\text { O cuidado } \\
\text { espiritual } \\
\text { proporciona } \\
\text { conforto e o } \\
\text { encontro } \\
\text { existencial entre a } \\
\text { pessoa em } \\
\text { cuidados } \\
\text { paliativos e os } \\
\text { profissionais da } \\
\text { equipe que o } \\
\text { cuidam. }\end{array}$ \\
\hline $\begin{array}{c}\text { Lima, } \\
\text { Machado } \\
\text { (2018) }\end{array}$ & $\begin{array}{l}\text { Psicologia: } \\
\text { Ciência e } \\
\text { Profissão }\end{array}$ & $\begin{array}{l}\text { Compreender os } \\
\text { sentidos e } \\
\text { significados } \\
\text { atribuídos pelos } \\
\text { cuidadores } \\
\text { principais à } \\
\text { experiência de } \\
\text { acompanhament } \\
\text { o de pacientes } \\
\text { com câncer. }\end{array}$ & $\begin{array}{c}\text { Realizou como } \\
\text { recurso } \\
\text { metodológico } \\
\text { uma pesquisa } \\
\text { qualitativa } \\
\text { exploratória, } \\
\text { utilizando a } \\
\text { observação } \\
\text { participante. }\end{array}$ & $\begin{array}{l}\text { Extraíram cinco } \\
\text { categorias } \\
\text { temáticas: A } \\
\text { espiritualidade } \\
\text { atribuindo } \\
\text { sentido à } \\
\text { experiência; O } \\
\text { tempo de } \\
\text { espera; Morte } \\
\text { como alívio do } \\
\text { sofrimento; } \\
\text { Revisão da } \\
\text { história de vida; } \\
\text { Incerteza quanto } \\
\text { ao futuro. }\end{array}$ & $\begin{array}{l}\text { A comunicação } \\
\text { da equipe ao } \\
\text { cuidador sobre a } \\
\text { aproximação da } \\
\text { morte pode } \\
\text { contribuir para o } \\
\text { processo de } \\
\text { elaboração } \\
\text { psíquica desta } \\
\text { vivência. }\end{array}$ \\
\hline
\end{tabular}

Fonte: Autores do estudo, 2019.

\section{Discussão}

O cuidado paliativo preza pela qualidade de vida tanto para o paciente enfermo quanto para a sua família. Eles são incorporados ao tratamento de um paciente a partir do diagnóstico 
de alguma doença, seja ela aguda ou crônica, que ameace a continuidade da vida. A espiritualidade no momento de enfrentamento de uma doença terminal é vista como uma ferramenta importante e que traz resultados significativos (FROSSARD, 2016). O sistema único de saúde (SUS) tem um papel decisivo na promoção dessa assistência paliativa humanizada.

A resolução No 41, DE 31 DE OUTUBRO DE 2018 normatiza que o Sistema Único de Saúde (SUS) deve ofertar gratuitamente cuidados paliativos como parte dos cuidados continuados incluído no âmbito do SUS, o qual diz respeito ao tratamento e cuidados destinados a toda pessoa acometida por uma doença que ameace a vida, podendo ser crônica ou aguda, como por exemplo, as doenças: neurodegenerativas, e as demências: Alzheimer e Parkinson (BRASIL, 2018).

De acordo com o coordenador Geral de Atenção Especializada, Sandro Martins:

\begin{abstract}
"Essa normativa é um avanço, já que orienta sobre o acesso aos cuidados paliativos nos serviços de saúde através do SUS. Os cuidados paliativos envolvem um diálogo aberto com o paciente e família sobre os objetivos do cuidado, voltados para preservar a qualidade de vida. A equipe multidisciplinar tem o papel de colaborar no cuidado integral para pessoas com doenças ou condições clínicas que ameacem a vida, desde o momento do diagnóstico, para aliviar sintomas, e principalmente a dor física"
\end{abstract}

Qual é o real sentido da vida? Segundo Bertachini e Pessini (2010), Para o enfermo compreender é preciso que antes sejam respondidas três perguntas: de onde vim? Por que estou aqui? Para onde vou? Todas essas perguntas-chave podem ser respondidas através das experiências religiosas e/ou espirituais do paciente. Quando não se tem ao longo da vida uma conexão com o transcendental, muitos pacientes se vêem fragilizados e com medo da morte, pois, pelo fato de eles não terem consciência do seu propósito, eles se sentem impotentes. Dessa maneira, a atuação do paliativista é de suma importância, porque, além do seu papel de confortar, cuidar e sanar as dores do paciente terminal, ele deve ajudar o paciente e a família ante o processo de compreensão e aceitação para que não seja uma etapa mais dolorosa do que já é (FERREIRA; SOUZA; STUSHI, 2018).

As pessoas que estão sob cuidados paliativos esperam dos profissionais da saúde uma forma de confirmação para que elas se sintam confiantes e em paz em relação ao processo de terminalidade. Porém, no Brasil, não se tem um serviço completo de cuidados paliativos, então muitos profissão não estão capacitados para lidarem com o pilar espiritual dos pacientes (CERVELIN; KRUSE, 2014). Mas o que os impede de atenderem as necessidades espirituais

414 Id on Line Rev. Mult. Psic. V.13, N. 45, p. 405-419, 2019 - ISSN 1981-1179 Edição eletrônica em http://idonline.emnuvens.com.br/id 
deles? Essa é uma questão trazida por Pérez-García (2016) e respondida por Arrieira, et al. (2017) em que alguns participantes da entrevista afirmam que a insegurança que demonstram aparece pelo fato de os profissionais não conhecerem a sua própria espiritualidade. Não porque são ignorantes, mas porque não têm tempo de se indagarem sobre, assim, acabam deixando de lado essa questão e dando valor e preferência ao lado científico. Então, quando os profissionais da saúde se deparam com um paciente de muita crença, eles acabam não sabendo lidar, no sentido de incentivar a fé nos pacientes para que consigam enfrentar seus problemas.

Quando a assistência paliativa demonstra compaixão e compreende o lado espiritual, ela dá aos pacientes e a família a crença no inatingível, dando-lhes força e disposição para enfrentarem os tratamentos da doença ou simplesmente o prolongamento de suas vidas e dá também esperança e conforto para uma morte tranquila e sem angústias ou uma possível cura (SILVA; MARCON; SALES, 2014).

Segundo o autor Júnior, et al. (2015), há divergências entre os significados de religião e espiritualidade, mas na visão de Bertachini e Pessini (2010) existe a definição de cada termo, porém eles são tratados com complementaridade. Entretanto, todos os artigos usados na revisão deste trabalho convergem em uma única resposta: a espiritualidade, a fé e a religião são importantes para o enfrentamento da doença crônica.

Existem necessidades espirituais em pacientes terminais que não devem ser desprezadas pelos profissionais da saúde, tais como fazer as pazes com o inimigo, amar e ser correspondido, ser reconhecido, não carregar o fardo da culpa, estar em família, ser grato pelo que viveu, entre outros. Esses detalhes na vida de um paciente são muitas vezes importantes para que ele passe para o processo de aceitação mais rápido (M, 2017).

Espiritualidade é algo particular de cada um. Arrieira, et al. (2017) corrobora com DalaiLama, o qual considera que a espiritualidade está relacionada com as qualidades do espírito humano, como: capacidade de perdoar, noção de responsabilidade, comportamento e harmonia, compaixão, tolerância, contentamento, no caso, virtudes que trazem felicidade para si mesmo e para as pessoas ao seu redor, como é bem relatado pelos participantes desse artigo.

Enquanto a religiosidade preza pela fé, rituais, devoção e crença em entidades, ela e a espiritualidade não devem ser tratadas como duas coisas distintas, pois elas se complementam (GRANITO; CURY, 2016). Após a análise do conteúdo, ficou claro que existem várias definições para a religião e espiritualidade, porém as pessoas que participaram das entrevistas

415 Id on Line Rev. Mult. Psic. V.13, N. 45, p. 405-419, 2019 - ISSN 1981-1179 Edição eletrônica em http://idonline.emnuvens.com.br/id 
tratam os dois termos como um só, como se fossem a mesma coisa. Essas pessoas não estão longe da realidade, já que esses termos versam em boa parte sobre os mesmos significados.

Além dos paliativistas, a família é o principal pilar para o bem-estar de um ente querido em necessidades de assistência por conta de alguma enfermidade (SILVA; ALVIM; MARCON, 2014). No momento de terminalidade, a família e os pacientes buscam uma forma de suprir a falta que eles por ventura devem ter feito em simples momentos da vida. Ambos contribuem com esse sentimento de necessidade de preencher o vazio que não foi vivido com plenitude (LIMA; MACHADO, 2018). Dessa forma, eles buscam fortalecer suas conexões existentes, como se fosse uma forma de compensação pelo passado. Portanto, são observados conforto e valoração nessa reconexão (SEREDYNSKYJ; RODRIGUES; DINIZ; FHON, 2014). Assim, o sentido da vida é uma construção feita ao longo da idade e compreendida ante uma situação que faz a pessoa refletir sobre sua existência.

Os profissionais da saúde vêm buscando estudar mais a respeito da espiritualidade, tornando-se imprescindíveis para um cuidado integral para o paciente, ademais, tem como objetivo a associação das interações durante o processo do trabalho em saúde, proporcionando bem-estar e qualidade de vida dos profissionais. (ARRIEIRA; et al., 2011).

\section{Conclusões}

A espiritualidade é o refúgio de famílias e pacientes em estado terminal, que necessitam do cuidado paliativo não só para o alívio das dores físicas, mas das dores emocionais e relacionamentos envolvidos no processo do cuidado. É portanto a resposta necessária ao clamor da espiritualidade dos pacientes e familiares, como a execução do bem-estar superior.

Por conseguinte, é evidente uma intrínseca relação entre o cuidado paliativo e a espiritualidade, e como esses dois pilares são esseciais à qualidade de vida do paciente, especialmente ao terminal. Dessa forma, é importante que a equipe multidisciplinar compreenda e seja sensível às necessidades espirituais do paciente para promover o cuidado integralizado, que por vezes é ignorado pelas diretrizes curriculares no modelo cartesianoflexneriano (SOUZA; PESSINI; HOSSNE, 2012).

O tema espiritualidade, por suas propriedades subjetivas, apresenta adversidades para a realização de sua abordagem de forma científica e objetiva (SILVA DA SILVA, 2011). Assim, 
é necessária a ampliação dos conhecimentos em relação à espiritualidade por meio de pesquisas científicas de viés qualitativo, principalmente no âmbito nacional, para que os profissionais de saúde possam apoderar-se dela como ferramenta do cuidado para empregá-la na atenção aos pacientes sob cuidados paliativos.

\section{Referências}

ARRIEIRA, Isabel Cristina de Oliveira et al. O sentido do cuidado espiritual na integralidade da atenção em cuidados paliativos. Revista Gaúcha de Enfermagem, [s.1.], v. 38, n. 3, p.1-9, 12 abr. 2018. FapUNIFESP (SciELO). http://dx.doi.org/10.1590/1983-1447.2017.03.58737.

ARRIEIRA, Isabel Cristina de Oliveira; et al. Espiritualidade na equipe interdisciplinar que atua em cuidados Paliativos às pessoas com câncer. Ciência, Cuidado \& Saude, v. 10, n. 2, p. 314-321, abril/junho, 2011.

BERTACHINI, Luciana; PESSINI, Leo. A importância da dimensão espiritual na prática dos cuidados paliativos. Revista Bioethikos, Rio de Janeiro, v. 4, n. 3, p.315-323, 2010.

BRASIL, Ministério da Saúde. Ministério da Saúde normatiza cuidados paliativos no SUS, Brasília, 2018. Disponível em: <http://portalms.saude.gov.br/noticias/agencia-saude/44723ministerio-normatiza-cuidados-paliativos-no-sus >. Acesso em: 14 de março de 2019.

CERVELIN, Aline Fantin; KRUSE, Maria Henriqueta Luce. Espiritualidade e religiosidade nos cuidados paliativos: conhecer para governar. Esc. Anna Nery, Rio de Janeiro, v. 18, n. 1, p. 136-142, Mar. 2014 . Disponível em: <http://www.scielo.br/scielo.php?script=sci arttext\&pid=S1414-81452014000100136\&lng=en\&nrm=iso>. Acesso em: 08 Feb. 2019. http://dx.doi.org/10.5935/1414-8145.20140020.

CERVELIN, Aline Fantin; KRUSE, Maria Henriqueta Luce. Espiritualidade e religiosidade nos cuidados paliativos: conhecer para governar. Escola Anna Nery, v. 18, n. 1, p. 136-142, 2014.

FERREIRA, Noeli Marchioro Liston Andrade; SOUZA, Claudenice Leite Bertoli de; STUSHI, Zaiana. Cuidados paliativos e família. Revista de Ciências Médicas, Campinas, v. 17, n. 1, p. 33-42, janeiro/fevereiro, 2018.

FROSSARD, Andrea. Os cuidados paliativos como política pública: notas introdutórias. Caderno EBAPE.BR, Rio de Janeiro, v. 14, edição especial, n. 12, p. 640-655, julho, 2016.

GRANITO, Marlene Pereira; CURY, Marina Rachel Graminha. A espiritualidade na prática pediátrica. Revista Bioética, v. 24, n. 1, p. 49-53, 2016. 
JÚNIOR, Eli Ávila Souza; et al. Religião no tratamento da doença renal crônica: comparação entre médicos e pacientes. Revista Bioética, v. 23, n. 3, p. 615-622, 2015.

LIMA, Carolina Pares de; MACHADO, Mariana de Abreu. Cuidadores principais ante a experiência de morte: seus sentidos e significados. Psicologia: ciência e profissão, v. 38, n. 1, p. 88-101, 2018.

MUÑOZ S. I. S. et al. Revisão sistemática de literatura e metanálise: noções básicas sobre seu desenho, interpretação e aplicação na área da saúde. In: Anais do $\mathbf{8}^{\circ}$ Simpósio Brasileiro de Comunicação em Enfermagem; 2002, nov 6-11; São Paulo, Brasil [CD- ROM]. São Paulo:Universidade de São Paulo; 2002

PÉREZ-GARCÍA, Esteban. ENFERMERÍA Y NECESIDADES ESPIRITUALES EN EL PACIENTE CON ENFERMEDAD EN ETAPA TERMINAL. Enfermería: Cuidados Humanizados, [s.1.], v. 5, n. 2, p.41-45, 2 dez. 2016. Universidad Catolica de Uruguay. http://dx.doi.org/10.22235/ech.v5i2.1286.

PÉREZ-GARCÍA, Esteban. Enfermería y necesidades espirituales en el paciente con enfermedad em etapa terminal. Enfermería: cuidados humanizados, v. 5, n. 2, p. 41-45, 2016.

RIVEROS RIOS, M. Aspectos bioéticos desde la visión personalista de la espiritualidade en el manejo de las personas en el área de la salud. Anales de la Facultad de Ciências Médicas, Asunción, v. 50, n.1, 2017.

SEREDYNSKYJ, Fernanda Laporti et al. Percepção do autocuidado de idosos em tratamento paliativo. Revista Eletrônica de Enfermagem, Goiânia, v. 16, n. 2, p.286-296, 30 jun. 2014. Universidade Federal de Goias. http://dx.doi.org/10.5216/ree.v16i2.22795.

SEREDYNSKYJ, Fernanda Laporti; RODRIGUES, Rosalina Aparecida Partezani; DINIZ, Marina Aleixo; FHON, Jack Roberto Silva. Percepção do autocuidado de idosos em tratamento paliativo. Revista Eletrônica de Enfermagem, v. 16, n. 2, p. 286-296, abril/junho, 2014.

SILVA DA SILVA, Denis Iaros. Significados e práticas da espiritualidade no contexto dos cuidados paliativos em pacientes oncológicos adultos. Clinical \& Biomedical Research, [S.1.], v. 31, n. 3, oct. 2011. ISSN 2357-9730.

SILVA, Maria Raquel Bertoli da et al. O câncer entrou em meu lar: sentimentos expressos por familiares de clientes. Revista de Enfermagem, Rio de Janeiro, v. 16, n. 1, p.70-75, mar. 2008.

SILVA, Vladimir Araujo da; MARCON, Sonia Silva; SALES, Catarina Aparecida. Percepções de familiares de pessoas portadoras de câncer sobre encontros musicais durante o tratamento antineoplásico. Rev. bras. enferm., Brasília, v. 67, n. 3, p. 408-414, June 2014. Disponível em: $\quad$ http://www.scielo.br/scielo.php?script=sci_arttext\&pid=S003471672014000300408 \&lng=en\&nrm=iso>. Acesso em: 08 Feb. 2019. http://dx.doi.org/10.5935/00347167.20140054. 
SILVA, Vladmir Araújo da; ALVIM, Neide Aparecida Titonelli; MARCON, Sonia Silva. Significado e sentido da identidade musical de pacientes e familiares sob cuidados paliativos oncológicos. Revista Eletrônica de Enfermagem, v. 16, n. 1, p. 132-141, janeiro/março, 2014.

SILVA, Vladmir Araújo da; MARCON, Sonia Silva; SALES, Catarina Aparecida. Percepções de familiares de pessoas portadoras de câncer sobre encontros musicais durante o tratamento antineoplásico. Revista Brasileira de Enfermagem, v. 67, n. 3, p. 408-414, maio/junho, 2014.

SOUZA JÚNIOR, Eli Ávila et al. Religião no tratamento da doença renal crônica: comparação entre médicos e pacientes. Revista Bioética, [s.1.], v. 23, n. 3, p.615-622, dez. 2015. FapUNIFESP (SciELO). http://dx.doi.org/10.1590/1983-80422015233098.

SOUZA, Virgínio Cândido Tosta de; PESSINI, Leo; HOSSNE, William Saad. Bioética, religião, espiritualidade e a arte do cuidar na relação médico-paciente. Revista Bioethikos, São Paulo, v. 6, n. 2, p.181-190, nov. 2012. Disponível em: <http://www.saocamilosp.br/pdf/bioethikos/94/a7.pdf>. Acesso em: 21 mar. 2019.

\section{Como citar este artigo (Formato ABNT):}

OLIVEIRA, Italo Constâncio de; FEITOSA, Pedro Walisson Gomes; SANTOS, Elaíne Apolinário dos; GIRÃO, Milena Maria Felipe; OLIVEIRA, Érika Galvão de; CARMO, Fábio Angelo do; OLIVEIRA, Isadélia Constâncio de. Cuidados paliativos e espiritualidade no Sistema Único de Saúde: Uma Revisão sistemática da literatura. Id on Line Rev.Mult. Psic., 2019, vol.13, n.45, p. 405-419. ISSN: 19811179 .

Recebido: 20/04/2019

Aceito 22/04/2019 